\title{
Erratum to: European Psychiatric/ Mental Health Nursing in the 21st Century
}

\author{
José Carlos Santos and John R. Cutcliffe
}

\section{Erratum to:}

J.C. Santos, J.R. Cutcliffe (eds.), European Psychiatric/Mental Health Nursing in the 21st Century, Principles of Specialty Nursing, https://doi.org/10.1007/978-3-319-31772-4

This book was initially published with errors in the following chapters, which have been updated now.

\section{Chapter 16}

https://doi.org/10.1007/978-3-319-31772-4_16

The affiliations have been updated.

\section{Chapter 17}

https://doi.org/10.1007/978-3-319-31772-4_17

The affiliations have been updated.

\section{Chapter 39}

https://doi.org/10.1007/978-3-319-31772-4_39

The reference section has been updated.

The updated online version of these chapters can be found at https://doi.org/10.1007/978-3-319-31772-4_16 https://doi.org/10.1007/978-3-319-31772-4_17 https://doi.org/10.1007/978-3-319-31772-4_39 